\title{
Skinner e Feyerabend sobre o Método e o Papel da Ciência em uma Sociedade Livre
}

\author{
César Antonio Alves da Rocha ${ }^{1}$ \\ Universidade Federal de São Carlos, São Carlos, SP, Brasil
}

\section{Resumo}

Da obra de B. F. Skinner fazem parte preocupações de ordem epistemológica, encerrando discussões sobre metodologia e critérios de verdade, e outras de ordem política e social, concernentes à relação entre ciência e sociedade. De um discurso, em alguns aspectos, coincidentes com uma forma de positivismo, Skinner passou a crítico de tendências puramente formalistas sobre o método científico, e de uma defesa do gerenciamento da sociedade por especialistas, passou a uma crítica à centralização do poder e à proposta de uma forma de organização baseada no controle face-a-face. Tratando de temas semelhantes, Paul Feyerabend desconstruiu a ideia de um método científico universal, denunciou um caráter potencialmente opressor da ciência, reclamando que o conhecimento científico não deveria ter inerente predileção sobre outras formas de conhecimento para o acesso às instituições de poder. Considerando a relevância da obra de ambos os autores para debates suscitados no âmbito da história e da filosofia das ciências, este trabalho objetiva apresentar e discutir aspectos do comportamentalismo radical, de Skinner, e do anarquismo epistemológico, de Feyerabend, que tratam de temas comuns. Conclui-se que, apesar de diferenças salientes, as duas perspectivas contêm algumas proposições convergentes e virtualmente complementares, cuja interlocução poderia ser útil a seus objetivos de busca por uma sociedade livre.

Palavras-chave: Filosofia da ciência, B. F. Skinner, Paul Feyerabend, Comportamentalismo radical, Anarquismo epistemológico.

\section{Skinner and Feyerabend on the Method and the Role of Science in a Free Society}

\begin{abstract}
B. F. Skinner's work encompasses epistemological concerns, including discussions about methodology and truth criteria, along with political and social ones, concerning the relationship between science and society. From a speech, in some aspects, coincident with a kind of positivism, Skinner came to criticize purely formalist tendencies about scientific method, and from the defense of the management of society by experts, he came to a criticism of the centralization of power and to the proposal of a form of organization based on face to face control. Dealing with similar topics, Paul Feyerabend deconstructed the idea of a universal scientific method, denounced an oppressive potential of science,
\end{abstract}

Endereço para correspondência: Al. dos Narcisos, 235, Apto. 32C, Cidade Jardim, São Carlos, SP, Brasil 13566-534. E-mail: alvesdarocha@gmail.com

Esse texto resulta de trabalho final apresentado à disciplina "Introdução à Filosofia da Ciência", cursada na condição de aluno especial, junto ao Programa de Pós-Graduação em Ciência, Tecnologia e Sociedade da Universidade Federal de São Carlos. O autor é aluno regular do Programa de Pós-Graduação em Psicologia da mesma universidade, e bolsista de doutorado da Fundação de Amparo à Pesquisa do Estado de São Paulo, processo 2014/02981-1. 
and claimed for scientific knowledge to have no inherent preference over other forms of knowledge to access to institutions of power. Considering the importance of both authors for the debates in the context of history and philosophy of science, this study aims to present and discuss aspects of Skinner's radical behaviorism and Feyerabend's epistemological anarchism that deal with common themes. We conclude that, although salient differences, both perspectives contain some convergent and virtually complementary propositions, whose dialogue could be useful to their pursuit of a free society.

Keywords: Philosophy of science, B. F. Skinner, Paul Feyerabend, Radical behaviorism, Epistemological anarchism.

\section{Skinner y Feyerabend sobre el Método y el Papel de la Ciencia en una Sociedad Libre}

\section{Resumen}

De la obra de B. F. Skinner forman parte preocupaciones epistemológicas, incluyendo discusiones sobre metodología y criterios de verdad, y políticas y sociales, sobre la relación entre ciencia y sociedad. De un discurso, en algunos aspectos, coincidente con una forma de positivismo, Skinner pasó a crítico de tendencias puramente formalistas del método científico, y de una defensa de la gestión de la sociedad por los expertos, pasó a una crítica a la centralización del poder y a la propuesta de una forma de organización basada en el control cara a cara. Tratando con temas similares, Paul Feyerabend deconstruyó la idea de un método científico universal, denunció el potencial opressivo de la ciencia, y afirmó que el conocimiento científico no tiene preferencia inherente sobre otras formas de conocimiento para acceder a las instituciones de poder. Este estudio tiene como objetivo presentar y discutir aspectos del conductismo radical de Skinner, y del anarquismo epistemológico, de Feyeratend, que tratan de temas comunes. Llegamos a la conclusión de que, aunque las diferencias sobresalientes, ambas perspectivas contienen algunas propuestas convergentes y prácticamente complementarias, cuyo diálogo podría ser útil para los objetivos de la búsqueda de una sociedad libre.

Palabras clave: Filosofía de la ciência, B. F. Skinner, Paul Feyerabend, Conductismo radical, Anarquismo epistemológico.

A obra de B. F. Skinner (1904-1990) é extensa, complexa, e sofreu influência de diferentes correntes filosóficas. De uma perspectiva, em alguns aspectos, simpática a uma forma de positivismo (cf. Skinner, 1938, p. 44), sua visão sobre a ciência sofreu contínuas transformações (Moxley, 1998), culminando em um discurso alinhado com filosofias como o pragmatismo e o darwinismo (Laurenti, 2012). Suas visões políticas, outrossim, parecem oscilar bastante, variando de um flerte com a tecnocracia, até tendências supostamente próximas ao anarquismo e à democracia direta (Lopes, 2015). A liberdade foi tema muito abordado por Skinner (1971), mas sua interpretação sobre a luta pela liberdade fez com que muitos o considerassem um inimigo da liberdade. Tomados em conjunto, esses aspectos dificultam a elaboração de uma "resposta skinneriana", singular e definitiva, à questão "qual é o papel da ciência em uma sociedade livre?".

Diversos filósofos e sociólogos da ciência contemporâneos se dedicaram ao problema, sendo Paul Karl Feyerabend (1924-1994) autor de alguns dos mais notáveis e polêmicos argumentos. Desconstruindo a noção canônica do que se sagrou como "método científico", Feyerabend (1975/1993) denunciou o caráter potencialmente opressor da ciência, chegando a alertar que a prevalência da ciência poderia representar uma ameaça à democracia (Feyerabend, 1978), como será explorado a seguir. A reação a tais declarações foi severa. Alguns criticaram a maneira como Feyerabend retratou episódios da história da ciência para fundamentar suas ideias (cf. 
Sokal \& Bricmont, 1998), e de "filósofo da ciência", Feyerabend chegou a ser alcunhado de "o mais perigoso inimigo da ciência" (Horgan, 1993, p. 36).

Mas uma apreciação atenta aos textos dos autores supracitados, que faça justiça à complexidade de suas formulações filosóficas, revela que, assim como Skinner não é inimigo da liberdade, Feyerabend não é inimigo da ciência. A despeito das diferenças salientes, que não são poucas, os esforços de ambos constituem contribuições relevantes a temas comuns. Explorando pontos de distanciamento e afinidades eletivas (no sentido de que são convergências possíveis, elencadas pelo autor deste texto), objetiva-se apresentar e discutir algumas ideias pontuais do anarquismo epistemológico, de Feyerabend, e do comportamentalismo radical, de Skinner. Justifica-se tal esforço tanto pela relevância de ambos os autores no contexto dos debates sobre o papel da ciência na sociedade, quanto pelo caráter inédito e contraintuitivo de tal aproximação. Por inesperado que possa parecer, aspectos de cada proposta poderiam ser vistos como complementares, configurando uma nova perspectiva, mais ampla e conciliatória, que embora então destoe daquelas que a originaram, poderia vir a constituir uma perspectiva promissora.

Para esse itinerário, serão examinadas considerações de ambos acerca do método científico, e, em seguida, descritas e comentadas suas visões sobre a relação entre ciência e sociedade. Tal divisão encerra duas partes principais, sendo que na primeira serão expostos aspectos virtualmente convergentes, e, na segunda, aspectos divergentes. Finalmente, encaminham-se breves reflexões a título de considerações finais.

\section{Convergências: Contra o Método, a Favor da Ciência}

Feyerabend foi um filósofo da ciência austríaco, bastante popular a partir da década de 1970, quando publicou duas importantes obras sobre filosofia e história das ciências, nomeadamente, Contra o Método e A Ciência em Uma Sociedade Livre, lançadas em 1975 e 1978. Doutorou-se em filosofia pela London School of Economics, sob a tutela de um personagem já bem conhecido no contexto da filosofia da ciência: Sir Karl Popper, cuja influência sobre Feyerabend repercutiu de maneiras diversas.

Ocorre que Popper era um racionalista e um liberal: sua principal obra, A lógica da pesquisa cientifica, encerra uma detalhada crítica aos cânones do positivismo lógico, além de uma nova proposta para a lógica da ciência (baseada em um procedimento de conjecturas e refutações) e para a sua demarcação, ao que se deu o nome de falsificacionismo. A perspectiva popperiana para a epistemologia é, assim, claramente prescritiva. Além de questões epistemológicas, o filósofo também escreveu sobre questões sociais e políticas, e em seu A Sociedade Aberta e seus Inimigos registrou duras críticas a diferentes formas de totalitarismo e a governos autoritários.

Considerando isso, poder-se-ia supor que a tendência anti-autoritária de Popper viu-se refletida na obra de Feyerabend, o que se expressaria em sua obstinada crítica ao emprego da ciência como esteio ao poder exercido por governos autoritários. Contudo, se há algo em que Popper e Feyerabend se distanciam decisivamente é em sua avaliação acerca do racionalismo. Apesar de ser o autor da primeira crítica de grande impacto à doutrina do positivismo lógico, Popper (1959/1972) preserva e amplia a tendência racionalista, com seu nominado "racionalismo crítico", no qual se vislumbra não apenas uma lógica universal sobre o empreendimento científico, como também a possiblidade de um conhecimento estritamente objetivo, cabendo à atitude racionalista iluminar o caminho que conduzirá ao desenvolvimento humano (cf. Marin, 2012).

Assim, conquanto Feyerabend pareça influenciado pela orientação liberal do tutor, se afasta da visão popperiana sobre a prioridade da razão e do conhecimento científico, e suas prerrogativas na busca por uma sociedade livre. Tal afastamento fica claro já em Contra o Método, onde lê-se: "A ciência é um empreendimento essencialmente anárquico: o anarquismo teórico é mais humanitário e mais suscetível de estimular o progresso do que suas alternativas representadas por ordem e lei" (Feyerabend, 1975/1993, p. 9). O autor ainda observa que embora não consi- 
dere o anarquismo a mais interessante proposta à filosofia política, considera-o um bom remédio para a epistemologia, por encorajar o questionamento produtivo de professados cânones essenciais do método científico.

Criticando a suposição de neutralidade, Feyerabend (1975/1993) reivindica uma perspectiva histórica, e não meramente formal, sobre o empreendimento científico:

É possível, naturalmente, simplificar o meio em que o cientista atua, através da simplificação de seus principais atores. Afinal de contas, a história da ciência não consiste apenas de fatos e de conclusões retiradas dos fatos. Contém, a par disso, ideias, interpretações de fatos, problemas criados por interpretações conflitantes, erros, e assim por diante. Análise mais profunda mostra que a ciência não conhece "fatos nus", pois os fatos de que tomamos conhecimento já são vistos sob certo ângulo, sendo, em consequência, essencialmente ideativos. Se assim é, a história da ciência será tão complexa, caótica, permeada de enganos e diversificada quanto o sejam as ideias que encerra; e essas ideias, por sua vez, serão tão caóticas, permeadas de enganos e diversificadas quanto as mentes dos que as inventaram. Inversamente, uma pequena lavagem cerebral muito fará no sentido de tornar a história da ciência mais insípida, mais simples, mais uniforme, mais "objetiva" e mais facilmente accessível a tratamento por meio de regras imutáveis. (p. 11)

Apesar da natureza plural da ciência, consequência da diversidade das "mentes dos cientistas", a educação científica tenderia sempre a simplificar a atividade científica, obliterando tudo aquilo que foge a uma reconstrução puramente racional. É a isso que o autor se refere ao falar em "lavagem cerebral": o modo como são ensinados e divulgados os achados científicos seria, nessa visão, um modo por meio do qual ensina-se também um ideário específico, que assevera a superioridade dessa forma de produção de conhecimento e todas as suas prerrogativas. Na ótica de Feyerabend, isso penetra a natureza dos fatos científicos, que passam a ser vistos como totalmente independentes das contingências que governam a ação dos cientistas.

Tal movimento constitui parte dos esforços que objetivam propagar a ideia de uma tradição científica que se mantém sempre una graças à observância das regras metodológicas que se pretendem universais. Feyerabend (1975/1993), porém, questiona: seria desejável dar apoio a uma tradição como essa? Sua reposta, é claro, será enfaticamente negativa, justificando-a com a constatação de que o próprio progresso científico se revela condicionado a uma independência em relação à uniformização metodológica. Vem daí a polêmica sobre seu apregoado aforismo: "o único princípio que não inibe o progresso é: tudo vale" (p. 14).

Posteriormente, há uma espécie retratação comedida, seguida da explicação de que tal aforismo não se trata exatamente de um "princípio" no sistema de pensamento de Feyerabend (1975/1993), mas de uma "exclamação estarrecida" daquele que observa a história de perto. Enumeram-se variados exemplos na história da ciência, principalmente na história da física, em vias de respaldar tal observação:

... não há uma só regra, embora plausível e bem fundada na epistemologia, que deixe de ser violada em algum momento. Torna-se claro que tais violações não são eventos acidentais, não são o resultado de conhecimento insuficiente ou de desatenção que poderia ter sido evitada. Percebemos, ao contrário, que as violações são necessárias para o progresso. Com efeito, um dos notáveis traços dos recentes debates travados em torno da história e da filosofia da ciência é a compreensão de que acontecimentos e desenvolvimentos tais como a invenção do atomismo na Antiguidade, a revolução copernicana, o surgimento do moderno atomismo (teoria cinética; teoria da dispersão; estereoquímica; teoria quântica), o aparecimento gradual da teoria ondulatória da luz só ocorreram porque alguns pensadores decidiram não se deixar limitar por certas regras metodológicas "óbvias" ou porque involuntariamente as violaram. (1975/1993, p. 14) 
Esse último aspecto, a "violação involuntária" de regras metodológicas, será especialmente providencial no estabelecimento de paralelos com o comportamentalismo de Skinner. Mas atendo-se ainda a Feyerabend, convém notar sua insistência, que chega a soar redundante, em afirmar que a maneira anárquica de proceder em ciência não é característica de algumas ciências em específico, ou de episódios isolados, mas algo que se revela necessário para o desenvolvimento do conhecimento científico em geral. Por isso há, além das ocasiões em que o pesquisador viola regras de forma involuntária, aquelas em que o faz de maneira deliberada.

Conforme Feyerabend (1975/1993), uma análise mais proximal do desenvolvimento das ciências revela diversos episódios em que a argumentação racional perde sua característica antecipadora para se tornar um obstáculo ao progresso científico. Quando isso acontece, mesmo os autoproclamados racionalistas recorrem a estratégias escusas à tradição científica formal. Há ocasiões em que

Até o mais rigoroso dos racionalistas se vê forçado a deixar de arrazoar, para recorrer à propaganda e à coerção, não porque hajam deixado de ser válidas algumas de suas $\mathrm{ra}$ zões, mas porque desaparecem as condições psicológicas que as tornavam eficazes e capazes de influenciar terceiros. (p. 16)

Mas se mesmo a argumentação racional não se vê a salvo, como seria possível sustentar que o princípio de "tudo vale" não equivaleria a uma forma de proceder completamente arbitrária e caótica? Buscando esclarecer esse ponto, o autor nota que é certo que padrões, modelos e normas metodológicas para a ciência existem, e possivelmente sempre existirão; no entanto, eles surgem a partir do próprio processo de pesquisa, e não de uma racionalidade antecipatória, puramente lógica. Entendido dessa forma, o "tudo vale" não significa a celebração da desordem na prática científica, mas, isso sim, que o estabelecimento de regras metodológicas depende da situação de pesquisa no momento presente, dentro de seu respectivo contexto e do conhecimento disponível no dado momento. Deve respeitar circunstâncias locais e correntes. Em uma palavra, deve ser contingente. Por isso as regras precisam ser constantemente "reinventadas", por vezes até em forma de "contra-regras", com ditames diametralmente opostos às regras metodológicas outrora empregadas.

Como exemplos de "contra-regras" que surgem na prática "oportunista" dos grandes cientistas, há a contra-indução e a introdução de hipóteses ad hoc, contrárias a princípios metodológicos básicos do indutivismo positivista e do racionalismo crítico popperiano. Uma considerável parte, se não a maior parte, da obra de Feyerabend consiste em análises detalhadas de episódios da história das ciências em que as supracitadas contra-regras se fazem presentes, com especial atenção às ciências físicas, e a personagens como Galileu Galilei (1564-1643) e Isaac Newton (1642-1727). É importante destacar, contudo, que tal exercício não se confunde com a proposição de uma nova metodologia científica, uma espécie de "metodologia anárquica". Segundo o próprio autor afirma, seus objetivos, mais descritivos que prescritivos, são mais modestos:

Alguém pode ter a impressão de que eu estou recomendando uma nova metodologia que substitui a indução pela contra-indução e que utiliza uma multiplicidade de teorias, pontos de vista metafísicos, contos de fada, ao invés do costumeiro par teoria/observação. Essa impressão seria equivocada, com certeza [itálicos adicionados]. Minha intenção não é de substituir um conjunto de regras gerais por outro; minha intenção é, ao invés disso, convencer o leitor que todas as metodologias, até mesmo as mais óbvias, têm seus limites [itálicos adicionados]. A melhor maneira de mostrar isto é demonstrar os limites e até a irracionalidade de algumas regras que todos consideram básicas. (Feyerabend, 1975/1993, p. 23)

Consideradas essas posições do anarquismo epistemológico de Feyerabend, cabe agora examinar de que forma poderiam encontrar paralelo no comportamentalismo de B. F. Skinner.

Skinner foi um psicólogo estadunidense, prógono do comportamentalismo radical, filosofia subjacente à sua proposta científica: a análise 
do comportamento. Suas primeiras publicações relatavam experimentos com ratos e pombos, avançando para uma extrapolação dos achados experimentais para a compreensão do comportamento humano individual e social, e da evolução das culturas, a partir de uma perspectiva selecionista. Ao longo de seis décadas, suas proposições teóricas e metodológicas sofreram mudanças profundas (cf. Laurenti, 2012; Moxley, 1999). Diferentes concepções de ciência podem ser derivadas a partir da análise do comportamento, conforme Skinner a descreveu em várias ocasiões, sendo que talvez uma das definições mais notórias é aquela que concebe o conhecimento científico como uma forma de comportamento verbal. Nas palavras de Skinner (1974),

O conhecimento científico é comportamento verbal, embora não necessariamente linguístico. É um corpo de regras para a ação eficaz, e há um sentido especial em que poderia ser "verdadeiro" se produzir a ação mais eficaz possível. Mas as regras nunca são as contingências que descrevem; permanecem sendo descrições e sofrem as limitações inerentes ao comportamento verbal. (p. 259)

Reconhecendo uma limitação intransponível do conhecimento científico imposta pelas variáveis controladoras do comportamento do cientista, Skinner se afasta de perspectivas representacionistas, elaborando uma interpretação sobre o conceito de verdade que o aproxima do critério pragmatista. As regras das ciências, incluídas aí as regras metodológicas, não espelham as contingências como elas são: tratam-se apenas de enunciados capazes de guiar a ação humana eficazmente.

Compreender a ciência como comportamento verbal suscita ainda uma série de questões suplementares. Quais seriam as "limitações inerentes ao comportamento verbal" mais importantes para a compreensão da ciência segundo essa acepção? E qual seria a função do método científico para a produção desse tipo de conhecimento? Questões como essas preocuparam Skinner (1956), que admitiu que o atual estágio de desenvolvimento da ciência do comportamento limitava uma compreensão satisfatória acerca do comportamento científico. O texto em que tal declaração se apresenta talvez seja o mais profícuo para sondar afinidades eletivas com o anarquismo epistemológico: trata-se de Uma história de caso no método científico (Skinner, 1956). Nesse artigo, Skinner descreve cinco princípios, de forma bem-humorada e aparentemente intentando ironizar o rígido controle pretensamente exercido pela observância às regras metodológicas tradicionais. São eles: (a) quando encontrar algo de interessante, deixe tudo mais e estude aquilo, (b) alguns modos de pesquisar são mais fáceis que outros, (c) algumas pessoas têm sorte, (d) a aparelhagem às vezes quebra, e (e) serendipidade, ou seja, ao procurar uma coisa, às vezes encontra-se outra.

Cada um desses princípios é ilustrado com exemplos de achados importantes, como a descoberta do registro cumulativo, da curva de extinção, e dos esquemas de reforçamento, a que se seguiu o abandono do conceito de reserva de reflexos. É especialmente interessante notar que em meio à descrição de tais princípios, Skinner (1956) declara (em tom possivelmente irônico): "Uma vez que eu não desejo depreciar o método hipotético-dedutivo, tenho o prazer de testemunhar aqui a sua utilidade" (p. 226). Tal declaração refere-se à suposta hipotetização a que Skinner recorreu no episódio em que, pela primeira vez, programou um esquema de reforçamento intermitente, e vai de encontro a declarações anteriores (e.g., Skinner, 1950, p. 215) em que o método hipotético-dedutivo é rechaçado, e a metodologia indutiva é ratificada como metodologia modelar da análise comportamental. Em sua avaliação da epistemologia comportamentalista radical, Chiesa (1994/2006) escreveu: "Enquanto estudantes de psicologia continuam a ser treinados principalmente nos métodos formais de teste e falsificação de hipóteses, o comportamentalismo radical é caracterizado por uma abordagem indutiva menos formal" (p. 53).

Por certo, o modo pelo qual a "formulação de hipóteses" inspirou o episódio narrado não se identifica com os procedimentos a que recorrem pesquisadores para os quais tal modelo é o método basilar de sua ciência: a fórmula popperiana de conjecturas e refutações nem de longe carac- 
teriza o padrão convencional de pesquisa em análise do comportamento. Contudo, isso não dirime tal episódio e os demais como amostra de um certo hibridismo: pelo modo como foi descrita e exemplificada em Uma história de caso..., a experiência prática do próprio Skinner destoa da rigidez metodológica prescrita por abordagens formalistas, como o positivismo lógico e o racionalismo crítico.

Além disso, é importante mencionar o contexto no qual Uma história de caso... fora escrito: por solicitação da American Psychological Association, diversos pesquisadores de renome foram solicitados a descrever os passos que seguiam na execução de suas pesquisas. A tal campanha deu-se o nome de Projeto A. Como aponta Dutra (2004, p. 181), "o Projeto A tinha claramente uma fundamentação filosófica baseada no positivismo lógico". O texto de Skinner (1956) veio em resposta a tal projeto, e os princípios por ele enunciados iam na contramão de uma sistematização lógica perfeita, da prática científica. Mais que isso, compreendido em seu contexto, o texto de Skinner pode ser encarado como uma espécie de manifesto subversivo ao status quo da metodologia científica à época sacralizada:

Skinner está claramente tentando subverter a ordem que os teóricos da metodologia científica queriam impor à pesquisa experimental. Seus cinco princípios e seus exemplos ilustrativos para cada um deles, tomados de seus anos iniciais de pesquisa em psicologia experimental, tentam, de fato, exprimir sua ideia de que não há regras nem padrões metodológicos impostos de fora e concebidos previamente ao próprio desenvolvimento contingencial da pesquisa científica. (Dutra, 2004, p. 181)

Destarte, ciente das limitações inerentes ao comportamento verbal, que descreve normas metodológicas, Skinner enumerou cinco "princípios" (que nada mais eram que recomendações derivadas de sua experiência de laboratório) em vias de alertar para o fato de que só uma maior compreensão acerca do comportamento humano poderia lançar luz sobre os aspectos mais decisivos da ciência. O conhecimento disponível até então era bastante limitado, e só sua expansão garantiria uma melhor compreensão sobre o processo científico: "Nós não sabemos o suficiente sobre o comportamento humano para saber como o cientista faz o que faz" (1956, p. 221). Curiosamente, embora o discurso de Skinner (1950) sobre a prioridade do indutivismo e do modelo de sujeito único contraste com a tendência não-prescritiva de Feyerabend, à semelhança do anarquismo epistemológico, o comportamentalismo skinneriano também considera que sistematizações meramente formais sobre o método não são suficientes para dar conta da ciência tal como ela é.

Como em Feyerabend (1975/1993), em Skinner (1956) nota-se um interesse maior em descrever limitações do modelo corrente e recomendar sua não-hegemonização, do que em preceituar uma alternativa: "quando finalmente tivermos uma abordagem empírica adequada do comportamento do homem pensante, vamos entender tudo isso. Até lá, pode ser melhor não tentar encaixar todos os cientistas em um único molde [itálicos adicionados]" (Skinner, 1956, p. 233).

\section{Divergências: O Papel da Ciência em Uma Sociedade Livre}

No ensaio 'Ciência.' O mito e seu papel na sociedade, Feyerabend (1975) introduz questões que ultrapassam um escopo meramente epistemológico: são questões que passam a tratar de elementos típicos da sociologia da ciência. É um dos textos em que se apresentam algumas de suas proposições mais explosivas, que só seriam melhor desenvolvidas três anos depois, com a publicação de A Ciência em Uma Sociedade Livre. Um dos pontos abordados por Feyerabend (1975) refere-se à relação entre a ciência e o estado, e mais especificamente os processos educativos e o ensino de ciências:

Uma ciência que insiste em ser a detentora do único método correto e dos únicos resultados aceitáveis é ideologia, deve ser separada do Estado e, especialmente, dos processos de educação . . . Um cidadão amadurecido não é um homem que foi instru- 
ído em uma ideologia especial - como o puritanismo ou o racionalismo crítico - $\mathrm{e}$ que agora é portador dessa ideologia, como de um tumor mental; um cidadão amadurecido é uma pessoa que aprendeu a tomar decisões e que decidiu em favor daquilo que mais lhe convém. É pessoa de alguma solidez espiritual (não se apaixona pelo primeiro trovador ideológico que lhe cruze o caminho) e que, portanto, está apta a escolher conscientemente a tarefa que lhe pareça mais atraente, em vez de deixar-se dominar por ela. Preparando-se para essa escolha, a pessoa estudará as ideologias mais importantes em termos de fenômenos históricos, estudará a ciência como fenômeno histórico e não como o único e sensato meio de enfrentar um problema. Estudará a ciência a par de outros contos de fadas, tais como os mitos de sociedades "primitivas", de sorte a contar com as informações necessárias para chegar a uma decisão livre. Parte básica de uma educação geral dessa espécie são conhecimentos dos principais propagandistas de todos os campos, de modo que o neófito possa desenvolver resistência contra todas as formas de propaganda, incluindo a propaganda que se denomina "argumento". Somente após esse processo de endurecimento será ele chamado a pronunciar-se em face das questões racionalismo-irracionalismo, ciência-mito, ciência-religião e outras questões semelhantes. A decisão que tome em prol da ciência - admitindo que a tome será muito mais "racional" do que é hoje qualquer decisão em favor da ciência. (pp. 175-176)

A defesa de que a forma como se ensina ciência seja orientada por uma perspectiva histórica ajuda a entender, a um só tempo, por que Feyerabend não é um inimigo da ciência, bem como por que tantos insistiram em assim classificá-lo. O que se constata em Feyerabend (1975) é simplesmente uma defesa de que a ciência seja ensinada de um ponto de vista histórico, e que esse ponto de vista não mascare seus embaraços típicos. Ao contrário: que se dê relevo à natureza contingencial e humana da produção de conhe- cimento em ciência, e não mais se busque propagar a ideia de que há um método áureo e um modelo uno de se pensar cientificamente.

Uma vez que se optasse por uma abordagem histórica, em que a ciência como disciplina passe a ser ensinada a partir de episódios tangíveis, detalhados em suas peculiaridades, cairia por terra o establishment de acordo com o qual seria possível vislumbrar ideais universais de método científico. É uma defesa de que se ensine a ciência como ela é, "encarnada" nos cientistas, contaminada por suas idiossincrasias, situada historicamente, e irremediavelmente influenciada pelas circunstâncias. Aqueles afeitos aos tradicionalismos da ciência moderna certamente não veriam com bons olhos a priorização da contingência no lugar da universalidade, da historicidade no lugar da incondicionalidade, e talvez isso explique em parte a reação depreciativa com a qual as propostas de Feyerabend foram recebidas.

Mas essa é apenas parte da controvérsia: Feyerabend (1975) reclama não apenas uma perspectiva histórica para o ensino de ciências, mas também defende que a ciência seja ensinada como um saber como outros, e que não possua nenhum privilégio de antemão sobre os demais saberes. Uma vez introduzidos a abordagens científicas e não-científicas sobre os "mesmos" fenômenos, ou fenômenos "análogos", indivíduos estariam em melhor condição de comparar, avaliar e deliberar sobre os tipos de explicação que melhor lhes sirvam. Deveras interessante é que Feyerabend (1975) defende essa coexistência entre ciência e não-ciência no âmbito do ensino como fator decisivo para que aqueles que optarem pela ciência o façam de maneira racional, ponderando os benefícios da explicação científica em relação a formas de explicação menos razoáveis. Pois somente com a ciência colocada em posição de igualdade para competir com outras formas de conhecimento é que os indivíduos estariam em condição justa e legítima de optar pela explicação científica por convicção de que suas virtudes são, em algum sentido, melhores, superiores, mais convenientes ou mais efetivas para satisfazer as necessidades que tais indivíduos consideram que deveriam ser satisfeitas. 
Nesse sentido, o anarquismo epistemológico se aproxima de algumas tendências da filosofia pragmatista contemporânea, que igualmente critica a noção de "discursos privilegiados". Talvez não haja melhor representante de tal tendência do que Rorty (1998), filósofo que operou uma atualização do pragmatismo clássico, e que afiança: "a ciência, a religião e as artes são instrumentos para a satisfação de desejos. Nenhuma dessas áreas pode ditar, embora qualquer uma delas possa e deva sugerir, quais desejos ter ou qual hierarquia avaliativa erigir" (p. 199). $\mathrm{Na}$ crítica à suposição de privilégio incondicional da racionalidade científica e seu papel em uma sociedade que se pretende livre, Feyerabend (1975/1993) chega a mencionar a "filosofia pragmática", declarando:

Uma sociedade baseada na racionalidade não é inteiramente livre; tem-se de jogar o jogo dos intelectuais. Uma troca aberta, em contrapartida, é guiada por uma filosofia pragmática . . . Uma troca aberta respeita o parceiro, seja ele um indivíduo, seja uma cultura inteira, ao passo que uma troca racional promete respeito somente na estrutura conceitual de um debate racional. (pp. 227-228)

É difícil ler Feyerabend sem conjecturar como seriam os desdobramentos práticos de uma abordagem anarco-epistemológica no campo social. Diante, por exemplo, da reclamação de que a ciência esteja separada do estado na exata medida em que a religião está (ou deveria estar): como isso se poderia manifestar no contexto da vida em sociedade? Em relação ao ensino de ciências, como exposto, não é o caso de excluir a ciência, mas sim de fazê-la conviver com demais possibilidades de conhecimento, e garantir que sua pluralidade metodológica e suas limitações sejam salientadas em vez de eclipsadas. Ou seja, que se dê relevo aos imprevistos, percalços, acidentes, e que se previna a propagação da ideia de ciência como um campo de saber superior e metodologicamente monolítico.

Outra repercussão prática do anarquismo epistemológico envolveria mudanças nas relações de poder entre especialistas e leigos. O parecer dos especialistas, afirma-se, é muitas vezes preconceituoso e carente de controle por fontes externas à própria ciência. Essa é uma preocupação especialmente relevante no campo político, onde é comum a aliança entre estado e ciência, fazendo com que propostas políticas sejam acreditadas pelo parecer dos cientistas. Nesse contexto, muitas vezes o argumento de escolha é o da unanimidade: a comunidade científica, tendendo sempre a convergir em direção à unanimidade, ofereceria melhor alicerce à deliberação política.

Em resposta a isso, Feyerabend (1978) inverte o argumento, notando que, não raro, é justamente a unanimidade um resultado de decisão política:

A unanimidade é muitas vezes resultado de uma decisão política: os dissidentes são suprimidos ou permanecem em silêncio para preservar a reputação da Ciência como uma fonte de conhecimento confiável e quase infalível. Em outras ocasiões, a unanimidade é resultado de preconceitos compartilhados: as posições são tomadas sem um exame detalhado do assunto sob inspeção e infundidas com a mesma autoridade da pesquisa detalhada. (p. 88)

Mas como proceder, afinal? Se não se devem basear em ciência as decisões políticas, em que, então, elas deveriam se basear? Em um mundo repleto de problemas sociais dramáticos, fomentar a suspeição diante de cientistas que buscam soluções possíveis parece ser tudo do que a humanidade não precisa no momento. Não obstante, a perspectiva de Feyerabend (1978) não reclama a exclusão da ciência e da racionalidade do campo político. Não se trata, pois, de destruir a ciência, mas de a destituir de uma posição de privilégio. Tal destituição significaria colocar a ciência em igualdade de condições na competição com formas alternativas de conhecimento, garantindo que tenham igualdade de acesso às instituições do poder.

Além disso, Feyerabend (1978) recomenda colocar a ciência sob o crivo de leigos que avaliem sua legitimidade. Tal proposta é levada pelo autor às últimas consequências, propondo que leigos, por geralmente serem aqueles diretamente envolvidos com os problemas aos quais 
a ciência se declara ocupada em resolver, deveriam deter o direito de supervisioná-la. A supervisão da ciência pelos leigos poderia ocorrer em setores diversos:

Comitês de leigos devidamente eleitos precisam examinar se a teoria da evolução está realmente tão bem estabelecida quanto os biólogos nos querem fazer crer, se o fato de estar estabelecida na opinião deles resolve a questão, e se ela deve substituir outras ideias nas escolas. Eles devem examinar a segurança de reatores nucleares . . - precisam examinar se a medicina merece a posição incomparável de autoridade teórica . . . Os comitês também devem examinar se a mente das pessoas é avaliada de forma adequada pelos testes psicológicos, o que se deve dizer sobre a reforma nos presídios $-\mathrm{e}$ assim por diante. Em todos os casos a última palavra não será dos especialistas, mas das pessoas diretamente envolvidas. (Feyerabend, 1978, pp. 120-121)

Um dos mais frequentes argumentos contrários afirma que essSe tipo de recomendação desvia atenção do problema maior, qual seja, a necessidade de instrumentalizar (leia-se, informar cientificamente) os leigos, para que então, e somente então, estivessem em legítima condição de avaliar o conhecimento científico. Feyerabend (1978), por certo, não esteve inadvertido de tal argumento: sua resposta, contudo, é que essa instrumentalização do leigo amiúde implicaria uma formação já alinhada com valores convencionais, nos quais o privilégio da ciência é presumido de antemão, e assim veiculado. Subjugar o leigo como incapaz, nesse sentido, equivaleria a subscrever à ideia de que na sociedade os intelectuais, por direito legítimo, é quem devem dar as cartas do jogo: ao anarquista epistemológico, isso seria precisamente o oposto de uma sociedade livre.

Para Feyerabend (1975/1999), a ciência "é uma disciplina intelectual que pode ser examinada e criticada por quem estiver interessado, e que parece difícil e profunda somente por causa de uma campanha sistemática de ofuscamento realizada por muitos cientistas" (p. 187). O mais importante, desse ponto de vista, é expandir a democracia de tal maneira que a grupo algum seja reservada a prerrogativa sobre o conhecimento científico. Horizontalizando dispositivos decisórios e radicalizando mecanismos democráticos tanto quanto o possível, a ciência não teria prerrogativa para servir à política como um tribunal. No lugar de uma racionalidade perfeita e incólume, a virtude mais desejável, nessa perspectiva, seria a maturidade, que por Feyerabend (1978) é entendida de maneira bastante particular: "A maturidade de que estou falando não é uma virtude intelectual, é uma sensibilidade que só pode ser adquirida por meio de contatos frequentes com pontos de vista diferentes" (p. 107, itálicos adicionados).

Passando, enfim, ao comportamentalismo, como seria possível articular proposições tão extravagantes como as de Feyerabend com o pensamento de Skinner sobre o papel da ciência em uma sociedade livre? Como afirmado anteriormente, os discursos políticos presentes no texto skinneriano são vulneráveis a interpretações diversas. Uma delas, conduz a uma proposta muito distante da de Feyerabend (1978): trata-se de uma forma de elogio à tecnocracia, um governo de técnicos, em que os processos de tomada de decisão estariam concentrados nas mãos de especialistas. É justamente uma realidade desse gênero a descrita na novela utópica Walden two (Skinner, 1948), uma sociedade em que a deliberação política se centraliza em um grupo de "planejadores", havendo pouco espaço para participação popular e a comunidade leiga.

Cabe ressaltar, porém, que Walden two, na ótica de Skinner (1948, 1969), descreve uma sociedade idealizada, igualitária, onde cidadãos gastariam poucas horas diárias com trabalho, e sem que fossem obrigados a tal, onde as artes e a ciência florescem e são incentivadas, e, teoricamente, onde estariam abolidas formas espoliativas de controle. Para garantir o ideal funcionamento da comunidade, uma junta de especialistas concentra o poder político, conduzindo a uma espécie de "gestão experimental" da cultura, na emblemática busca utópica por um mundo melhor. Skinner (1948) tenta justificar a ausência de participação popular nesse processo de maneira um tanto quanto inusitada, como se 
verifica na declaração do personagem Frazier, um dos planejadores:

O povo não está em condições de avaliar especialistas . . . O leigo não avalia a necessidade de experimentação. Exige que o especialista saiba. E é totalmente incapaz de aguentar o período de dúvida durante o qual um experimento se desenvolve. Os especialistas devem ou disfarçar seus experimentos e fingir que sabem o resultado antecipadamente, ou parar de experimentar inteiramente e lutar para manter o status quo. (Skinner, 1948, p. 251)

Seria possível argumentar que Walden two se trata apenas de um romance, logo, não seria honesto avaliar a posição de Skinner a partir do que ali resta escrito. Todavia, tais críticas poderiam ser respondidas por meio de declarações do próprio autor, que observou, em referência ao romance, em primeiro lugar, que "para alguns leitores o livro pode parecer ter sido escrito com ironia, mas foi na verdade uma proposta bastante séria" (Skinner, 1969, p. 199), e em segundo lugar, que "os pontos de vista de Frazier são essencialmente os meus próprios - mais agora do que quando eu os escrevi" (1983/1984, p. 9).

Logo, no que se refere ao papel do conhecimento científico para a organização social, e mais especificamente para a política, é um tanto quanto claro que, para Skinner (1948), pelo menos em uma das possíveis leituras que se pode fazer de sua visão política, a ciência e os cientistas devem, sim, ocupar posição privilegia$\mathrm{da}$, preferencialmente como gerentes, ou, mais precisamente, como planejadores da cultura. Trata-se de garantir, numa aposta contrária à de Feyerabend (1978), que o especialista comande o processo de deliberação política, excluindo-se a participação do leigo.

Apesar disso, uma leitura alternativa do discurso político skinneriano é possível: em Comportamento humano e democracia, publicado quase três décadas após Walden two, Skinner (1978) apresenta uma crítica à democracia representativa, acenando para possibilidades de organização social baseadas no que chama de "controle face a face", algo mais próximo à de- mocracia direta, ou participativa, podendo até mesmo ser lido como um discurso com tendências anarquistas. Trata-se de uma leitura bastante diversa da visão tecnocrática, fomentada pelo modelo de sociedade descrito em Walden two (cf. Lopes, 2015). Na descrição de tal possibilidade, encontra-se uma crítica à concentração de poder: "A concentração de poder em uma agência é condenável, não só porque ele é caracteristicamente mal utilizado e desperdiçado, mas porque destrói contatos interpessoais" (Skinner, 1978, p. 9).

A diferença importante a ser notada é entre um Skinner (1948) que defenderia o gerenciamento da sociedade por especialistas que concentram poder político, e um Skinner (1978) que advertiria que a concentração de poder por uma agência controladora implica que tal poder seria caracteristicamente mal utilizado: o que poderiam revelar essas inconsonâncias? É possível supor que, na ótica skinneriana, diferentemente de governo, religião, educação, psicoterapia e economia - instâncias detalhadamente descritas como agências de controle do comportamento (Skinner, 1953/2005) - a ciência não é vista como mais uma agência. Se a ciência será empregada para o bem ou para o mal, isso é algo que foge a seu próprio escopo: o problema não estaria na ciência per se, mas em suas aplicações.

Se isso estiver correto, a análise de Skinner (1953/2005) sobre o controle exercido pelas diferentes agências poderia ser vista como uma forma de emprego do conhecimento científico para a denúncia de abusos do poder instituído. A ciência serviria tanto aos controladores quando aos controlados - não seria mais libertária ou despótica por sua própria natureza. Os controlados se poderiam valer da ciência do comportamento para compreender em que medida o poder instituído os controla, e então se engajar em estratégias do que Skinner (1953/2005) chamou de contra-controle, a exemplo de fuga, revolta e resistência pacífica. Desse modo, o conhecimento fornecido pela análise do comportamento, ao viabilizar a compreensão e eventual desmantelamento de contingências opressivas, seria de especial interesse à luta pela liberdade. 


\section{Considerações Finais}

Ao longo do século XX, coexistiram discursos muito variados acerca da natureza da ciência e do método científico. Estabelecido nas primeiras décadas, o positivismo lógico foi progressivamente suplantado, especialmente da segunda metade do século em diante, primeiramente por conta das críticas de Popper (1959/1972), a que se seguiram perspectivas epistemológicas historicamente orientadas, sendo uma delas a de Feyerabend (1975/1993). Nesse ínterim, B. F. Skinner ocupava-se, sobretudo, com o estabelecimento de uma ciência do comportamento, dedicando-se, eventualmente, a discussões mais genéricas sobre a ciência e o método científico em geral. Em Skinner (1956), notam-se antecipações de algumas ideias que posteriormente surgiriam radicalizadas em traços do anarquismo epistemológico de Feyerabend.

Desse modo, a perspectiva de Skinner (1956) representa relativo pioneirismo, considerando que, até então, a tendência positivista lógica ainda preservava influência considerável, em paralelo com progressiva ascensão do racionalismo crítico. É certo que inúmeras disparidades podem ser assinaladas entre Skinner e Feyerabend. Mesmo sendo um empirista firmado, o primeiro possivelmente não referendaria o exasperado ataque de Feyerabend ao racionalismo. De maneira semelhante, é provável que na ótica deste último, o discurso skinneriano, conquanto pontualmente crítico de formalismos, jamais seria suficientemente subversivo a ponto poder ser considerado fiador de um anarquismo epistemológico. Mas afora as diferenças mais óbvias, ambos produziram, cada qual a seu modo, contribuições significativas para pensar a empresa científica a partir da experiência prática, historicamente situada, convergindo em direção a uma epistemologia menos formalista e universalista, e mais contingencial.

Em relação ao papel da ciência em uma sociedade livre, notam-se as divergências mais salientes entre Feyerabend e Skinner. Para o primeiro, em uma sociedade livre, a ciência não apenas deveria competir em posição de igualda- de com demais formas de conhecimento (tanto no contexto dos processos educativos, quanto na arena política), como também deveria se sujeitar à supervisão por leigos. Skinner, por seu turno, oscilando entre inspirações tecnocráticas e pró-anárquicas, ora recomendou o privilégio à ciência no âmbito da deliberação política e a concentração de poder político por especialistas, ora criticou a concentração de poder, ao passo em que preservou um otimismo em relação à ciência como instrumento providencial ao contra-controle e, consequentemente, à luta pela liberdade.

A título de desfecho, convém arriscar uma sugestão conciliatória: conquanto a olhos incautos aparentem ser pontos de vista, a um só tempo, extremistas e radicalmente antagônicos, as ideias de Skinner e Feyerabend, por inesperado que possa parecer, encerram proposições virtualmente complementares. Se, por um lado, de Skinner deriva-se tanto a proposta de uma atitude experimental em política, quanto um alerta sobre os problemas da concentração de poder, talvez valha a pena considerar vias que combinem o emprego da experimentação no campo do governo, com a mitigação dos riscos do poder concentrado.

Tal mitigação poderia, por exemplo, ser efetuada por meio da implementação da proposta de Feyerabend (1978) sobre conselhos de leigos, eleitos para supervisionar a ciência, abandonando-se, complementarmente, a recomendação do primeiro Skinner (1948) sobre a prerrogativa exclusiva dos especialistas em planejar a cultura. Os critérios de legitimação para os mecanismos de planejamento seriam, portanto, definidos por aqueles diretamente envolvidos com os problemas a serem resolvidos. O silêncio de Skinner sobre o papel da ciência como uma agência controladora poderia ser corrigido com auxílio dessa proposição de Feyerabend.

Adicionalmente, a constatação de Feyerabend (1975/1993) de que há, historicamente, uma relação íntima entre progresso e pluralismo metodológico poderia informar a proposta skinneriana de planejamento cultural. Galvanizado por uma atitude anarco-epistemológica, o planejamento poderia ver radicalizado seu caráter em- 
pírico, submetendo à experiência uma variedade de procedimentos, garantindo e expandindo sua multiplicidade, e até mesmo recorrendo a procedimentos, artifícios e técnicas provenientes de formas de conhecimento alheias à ciência. Assim, a tendência pragmatista de Skinner (1974), em se afastar do representacionismo e fazer da efetividade seu critério de verdade, poderia confluir com a tendência pragmatista de Feyerabend (1975/1993), que recusa conceber a ciência como discurso privilegiado. Uma absoluta rejeição à participação da ciência nos processos de gerenciamento da vida em sociedade, que poderia ser inspirada pelas críticas de Feyerabend (1978), mereceria ser revista a partir de um diálogo com algumas das ideias de Skinner (1971) em favor de uma cultura deliberadamente planejada.

Ressalte-se o caráter sabidamente polêmico da proposta aqui esboçada, a qual dificilmente encontraria guarida sob a perspectiva de cada um desses autores isoladamente. Não obstante, considera-se uma proposta auspiciosa justamente na medida em que procura abstrair de cada um deles aquilo que parecem oferecer de mais interessante, a exemplo do experimentalismo comportamentalista e do irredutível plurarismo de Feyerabend.

De que modo uma proposta como essa se veria efetivada na prática é uma questão que resta ser averiguada. Uma eventual coalizão entre o experimentalismo comportamentalista e o pluralismo anarco-epistemológico poderia gerar consequências tão inusitadas quanto imprevisíveis. Não obstante, parece se tratar de uma aliança promissora, posto que fiada por uma esperança pela qual vale a pena trabalhar, qual seja, a esperança de que a busca por um mundo melhor não obstrua o caminho em direção a uma sociedade mais livre.

\section{Referências}

Chiesa, M. (2006). Radical behaviorism: The philosophy and the science. Boston, MA: Authors Cooperative. (Original publicado em 1994)

Dutra, L. H. A. (2004). Behaviorismo, operacionalismo e a ciência do comportamento científico. Philósophos - Revista de Filosofia, 9(2), 179 206. doi:10.5216/phi.v9i2.3035.
Feyerabend, P. K. (1993). Against method. London: Verso. (Original publicado em 1975).

Feyerabend, P. (1999). How to defend society against science. In J. Preston (Ed.), Paul K. Feyerabend: Knowledge, Science and Relativism: Philosophical Papers Vol. 3 (pp. 181-191). Cambridge, MA: Cambridge University Press. (Original publicado em 1975).

Feyerabend, P. (1975). 'Science'. The myth and its role in society. Inquiry, 18(2), 167-181. doi:10.1080/00201747508601758

Feyerabend, P. K. (1978). Science in a free society. London: Verso.

Horgan, J. (1993, May). Profile: Paul Feyerabend The Worst Enemy of Science. Scientific American, 36-37.

Laurenti, C. (2012). O lugar da análise do comportamento no debate científico contemporâneo [The place of behavior analysis in the contemporary scientific debate]. Psicologia: Teoria e Pesquisa, 28, 367-376. doi:10.1590/S010237722012000300012 . doi:10.1590/S010237722012000300012

Lopes, C. E. (2015). The political discourses of behavior analysis. Operants, 27-32.

Marin, S. R. (2012). Intervenção social e desenvolvimento humano em Karl Popper. In P. E. Oliveira (Ed.), Ensaios sobre o pensamento de Karl Popper (pp. 252-273). Curitiba, PR: Círculo de Estudos Bandeirantes.

Moxley, R. A. (1998). Why Skinner is difficult. The Behavior Analyst, 21(1), 73-91.

Moxley, R. A. (1999). The two Skinners, modern and postmodern. Behavior and Philosophy, 27, 97-125. Recuperado em http://www.jstor.org/ stable/27759395

Popper, K. R. (1972). A lógica da Pesquisa Científica (L. Hegenberg, \& O. S. da Mota, Trads). São Paulo, SP: Cultrix. (Original publicado em 1959)

Rorty, R. (1998). Truth and progress: Philosophical papers III. Cambridge: Cambridge University Press.

Skinner, B. F. (1938). The behavior of organisms. New York: Appleton-Century.

Skinner, B. F. (1948). Walden two. New York: Macmillan. 
Skinner, B. F. (1950). Are theories of learning necessary? Psychological Review, 57, 193-216. doi:10.1037/h0054367

Skinner, B. F. (1956). A case history in scientific method. American Psychologist, 11, 221-233. doi:10.1037/h0047662

Skinner, B. F. (1969). Contingencies of reinforcement: A theoretical analysis. New York: Appleton-Century-Crofts.

Skinner, B. F. (1971). Beyond freedom and dignity. New York: Pelican Books.

Skinner, B. F. (1974). About behaviorism. New York: Alfred A. Knopf.

Skinner, B. F. (1978). Human Behavior and Democracy. In Reflections on Behaviorism and Society (pp. 3-15). Englewood Cliffs, NJ: Prentice Hall.
Skinner, B.F. (1984). A matter of consequences: Part three of an autobiography. New York University Press. (Original publicado em 1983)

Skinner, B. F. (2005). Science and human behavior. B. F. Skinner Foundation. (Original publicado em 1953). Recuperado em http://www.bfskinner. org/newtestsite/wp-content/uploads/2014/02/ ScienceHumanBehavior.pdf

Sokal, A., \& Bricmont, J. (1998). Fashionable nonsense: Postmodern intellectuals' abuse of science. New York: Picador.

Recebido: 04/01/2016

$1^{a}$ revisão: $13 / 04 / 2016$

Aceite final: 29/04/2016 